\title{
TECNOLOGIA ANALÓGICA E DIGITAL: NOVAS QUALIFICAÇÕES NO PROCESSO DE TRABALHO E DESAFIOS À EDUCAÇÃO
}

\author{
ANALOG AND DIGITAL TECHNOLOGY: \\ NEW SKILLS IN THE WORK PROCESS AND \\ CHALLENGES TO EDUCATION
}

Luiza Turnes*

Resumo: Neste livro que foi resenhado, fruto da tese de doutorado de Lucídio Bianchetti, o autor nos coloca diante da preocupação acerca das telecomunicações e nos conduz à discussão dos desafios representados, tanto pelos avanços científicos e tecnológicos quanto pela velocidade com que tais avanços se produzem. A partir disso, Bianchetti aprofunda a análise da passagem da tecnologia analógica à digital no setor de telecomunicações, sendo que seu objetivo não é apenas o de conhecer o desenvolvimento dessa mesma tecnologia, mas seus desdobramentos em termos da qualificação dos trabalhadores que atuam numa empresa - a Telesc. Neste caso, de um lado, enfrenta-se as demandas por novas qualificações dos trabalhadores nas empresas em processo de incorporação de inovações organizacionais e de base física e, de outro, questões que são levantadas a respeito do denominado "modelo de competências". Para finalizar, Bianchetti retoma o debate sobre as relações entre trabalho e educação e realiza, nesse sentido, uma interessante discussão a respeito da incursão do empresariado no campo educacional.

Palavras-chave: Tecnologias da Informação e Comunicação. Trabalho. Educação. 
Abstract: This book was reviewed as a result of the doctoral thesis of Lucídio Bianchetti, the author puts forth the concern about telecommunications and leads us to the discussion of the challenges posed by both the scientific and technological advances as the speed with which such advances are produced. From this, Bianchetti deepens the analysis of the transition from analog to digital technology in the telecommunications industry, and its goal is not only to know the development of such technologies, but its consequences in terms of qualification of workers who work in a company - the Telesc. In this case, on one side, facing up, demands for new skills for workers in companies in the merger process of organizational innovations and basic physics, and other, questions are raised about the so-called "competency model". Finally, Bianchetti resumes debate on the relationship between work and education and conducts, in this sense, an interesting discussion about the incursion of entrepreneurship in education.

Keywords: Information and Communication Tecnologies. Work. Education. 
A obra Da chave de fenda ao laptop: tecnologia digital e novas qualificações: desafios à educação, de Lucídio Bianchetti, está dividida em seis capítulos, os quais estão subdivididos em alguns tópicos que se desenvolvem basicamente em torno das Tecnologias de Informação e Comunicação (TIC), e a maneira como elas estão/ foram sendo implantadas dentro das empresas, especialmente na empresa de Telecomunicações de Santa Catarina (Telesc).

O autor discute os desafios representados, não só pelos avanços científicos e tecnológicos, mas, também, pela velocidade com que tais avanços se produzem, assim como pela sua rápida incorporação à vida pessoal e social. Na rotina das pessoas, em sua grande maioria, seja no trabalho, seja na execução de tarefas rotineiras ou no lazer, os meios, os equipamentos, as interfaces, bem como os próprios conteúdos, foram ou estão sendo velozmente digitalizados.

Para analisar esta questão, Bianchetti (2001) aponta-nos que essa inovação se deu por rupturas e gerou consequências dolorosas e até traumáticas para os trabalhadores, e para a empresa. $\mathrm{O}$ processo de desenvolvimento tecnológico dos meios de transmissão partiu dos antigos fios de cobre, passou pelo rádio, pelo satélite, chegando à fibra ótica, como uma revolução ímpar, uma vez que, pela digitalização de todo o processo (voz, imagem e dados), a transmissão passou a ser em bits e tornou-se possível a sua conversão em sistema binário.

Posteriomente, penetra-se no exame da passagem da tecnologia analógica à digital no setor de telecomunicações. Nesse novo contexto pessoas e instituições, com destaque para a escola, são conduzidas, por opção ou pela compulsoriedade a que são submetidos todos aqueles que aspiram manterem-se coetâneos ao seu tempo, a rever formas, métodos de aprender e ensinar, uma vez 
que a tradição, a experiência e a formação ou treinamento pontual deixaram de ser critério de qualificações para a vida, incluindo o trabalho. Aderir-se, apropriar-se, fazer uso individual e coletivo dessas criações humanas significa a possibilidade de domínio de quantidades de informações jamais pensadas e de novas formas de cruzá-las e ampliar a sua utilização.

As vantagens das tecnologias digitais, para a empresa e para os usuários, foram consideráveis, seja pela diminuída exigência de espaço físico, do tamanho dos equipamentos, pela redução dos custos de fabricação e manutenção, seja pela rapidez, confiabilidade, e até pela ampliação do leque de serviços. Para os trabalhadores, esse novo processo resultou em mudanças profundas no número de empregados e na qualificação deles determinada. Os técnicos, que continuaram na empresa, foram obrigados a abdicar de sua qualificação anterior e construir outra, com base em novos parâmetros. Segundo Bianchetti (2001), foram obrigados não a uma simples troca de habilidades, mas a construir uma nova síntese, em outro patamar, com desafios e aplicações bem diversas das anteriores.

Seguiremos, após um relato breve do livro, com a análise de cada capítulo.

No primeiro capítulo denominado "A polêmica em torno do processo de qualificação" Bianchetti (2001) discute a questão do processo de qualificação dos trabalhadores é cada vez mais complexa e de difícil definição, pois de um lado o capital direciona e controla o processo de trabalho, enquanto sujeito social, e de outro existem os trabalhadores que apresentam de forma muito particular seus saberes tácitos e suas estratégias de trabalho. Com isso, pode-se perceber que qualificação pode ser compreendida como o saber adquirido historicamente no processo geral do trabalho. 
Algumas ideias neoliberais apontam novas questões como a transição do conceito de "qualificação" para o modelo que "competência”. O trabalhador considerado qualificado é aquele que se diferencia dos demais por meio de seus conhecimentos, especialmente da aplicação desses conhecimentos, mediante sua forma de tratar certas situações, de mostrar-se interessado aos novos aprendizados e atento nos fatos corriqueiros ao seu redor. Se destacar como um profissional qualificado pode render vários benefícios ao trabalhador, como estabilidade profissional e melhorias salariais. Por outro lado, a representação de competência sobre qualificação tende a trazer novas demandas de conhecimentos na área da educação e do trabalho, tornando os conhecimentos anteriores defasados.

Acerca das qualificações (tele)tácitas, pode-se dizer que a possibilidade de comunicação e de troca de informações entre as empresas é um novo conflito. A comunicação entre os trabalhadores de diversas empresas do mundo tornou o campo do conhecimento do trabalho muito mais amplo. É como se o mundo se tornasse cada vez menor geograficamente. Isso possibilitou um melhoramento em alguns setores ou até mesmo nas empresas.

Outra questão de debate neste capítulo é o vão que está presente entre tarefas prescritas e tarefas realmente praticadas. O saber tácito que cada trabalhador conquista com o tempo e de maneira peculiar não é novidade. Anteriormente, esses saberes eram passados e trocados entre esses indivíduos de forma muito subjetiva, diferentemente do que vem acontecendo nos últimos tempos, com as novas TIC. A relação, a troca de ideias, de conhecimento entre os trabalhadores torna-se cada vez mais instigada, para que haja uma maior transformação tecnológica, organizacional e gerencial nas empresas. 
Portanto, pode-se afirmar, conforme Bianchetti (2001), que com as inovações tecnológicas e a informatização da sociedade acontece uma crescente demanda de aprendizado por parte dos trabalhadores no próprio local de trabalho. Isto é, o local onde supostamente se colocaria em prática seus conhecimentos providos da escola está assumindo o papel pedagógico escolar.

No segundo capítulo do livro, “Tecnologia de Informação e a 'Sociedade do Conhecimento"', Bianchetti (2001) enfatiza que as tecnologias estão ocupando um espaço cada vez maior no campo do trabalho, desempenhando funções de extrema importância, diminuindo fronteiras entre tecnologias e setores, até mesmo criando novos termos. As novas TIC possibilitam a transmissão de conteúdos vinculados a um novo espaço e tempo. A telemática, que surgiu da junção entre informática e telecomunicação, deu forma a um novo espectro tecnológico, no qual fica cada vez mais difícil diferenciar o que é da computação ou da telecomunicação. Toda essa inovação trouxe consigo a flexibilidade e integração entre as empresas. No pensamento econômico, houve uma redução nos custos, no espaço e no tempo de circulação e, assim, maior capacidade produtiva para as empresas.

Essa junção modificou, também, a forma de trabalho, pois as pessoas e os setores não trabalham mais de maneira tão dividida e subdividida e nem trabalham mais focados na matéria em si, mas sim em um produto mais abstrato, subjetivo, fazendo com que haja uma maior ampliação na capacidade de abstração do trabalhador, e este aspecto é fortemente trabalhado pelo autor durante o livro. Esse processo impõe ao trabalhador a construção de novas qualificações e a procura de novos conhecimentos.

O fato é que as novas TIC, conforme Bianchetti (2001), se apresentam como estratégia global do capitalismo e traz o estresse aos 
trabalhadores, sujeitando-os às novas exigências de qualificação para com os novos equipamentos. E essas inovações estão baseadas na diminuição do tempo e do espaço, controle do tempo e disciplinarização dos trabalhadores, e, além disso, a informação transformou-se um elemento de consumo, uma mercadoria com valor econômico cada vez mais evidente, que trouxe mudanças no processo de produção e circulação, já que a própria informação se apresenta como produtora de mercadorias e também como uma mercadoria em si no processo de trabalho.

Anteriormente, a informação era um meio para alcançarmos algum fim, agora, ela se tornou um fim que gira em torno de si mesmo. Conseguir informações é o passo principal para se formar e alcançar ao conhecimento, porém é necessário que seu possuidor seja ativo, para que a partir dos dados de informações nasça o conhecimento. Podemos caracterizar, assim, o conhecimento como sendo dependente das atitudes individuais de cada homem, tendo uma possibilidade maior de desenvolvimento por meio das novas TIC, que possibilitam grande veiculação de informações. Adquirir grande quantidade de informações não significa desenvolvimento, mas é preciso atitude humana para que essas informações se tornem úteis.

No terceiro capítulo do livro, "Aspectos Históricos das TICs", o autor tem como objetivo compreender as motivações subentendidas e explícitas que conduziram à criação e à disseminação da telefonia e outros meios que gradativamente são reunidos, da mesma forma que os diferentes estágios pelos quais este meio de comunicação foi passando, salientando a migração dos meios e equipamentos de transmissão e comutação da tecnologia analógica à digital, mencionando as repercussões desse processo de passa- 
gem acerca dos novos requisitos cognitivos e atitudinais referente a qualificação dos trabalhadores e de todos aqueles que de alguma forma precisam lidar com equipamentos teleinformáticos.

No quarto capítulo, "A qualificação na visão dos dirigentes, engenheiros e operadores de uma empresa de telecomunicações”, o autor desenvolveu linhas de pensamento por meio de entrevistas com funcionários da empresa Telesc. Por meio da pesquisa foi possível ter uma visão mais crítica e detalhada da realidade da empresa que possibilitou constar que, realmente, as preocupações estão voltadas para a qualificação. As novas tecnologias abriram uma discussão em torno dos termos "desqualificação" e requalificação. A troca de habilidades do trabalhador não é nada simples, não é como simplesmente trocar alguma peça de lugar e substituir por outra. É mais complexo e trabalhoso do que isso.

De acordo com Bianchetti (2001), o modo como as novas tecnologias e a forma de gerenciamento que vem sendo implantados nas empresas trazem consequências aos trabalhadores, ainda desprovidos do conhecimento necessário para abstrair tamanha mudança no sistema de trabalho. O processo de migração da tecnologia analógica à digital foi um processo de grande mudança para os entrevistados, tanto no espaço físico, como em equipamentos, quanto na qualificação. Alguns acreditam que as novas tecnologias proporcionaram para os trabalhadores uma maior sofisticação no ambiente do trabalho, e que, com a preparação dada pela empresa, os trabalhadores estariam aptos ao novo meio de trabalhar. Todavia, para muitos deles, principalmente para os trabalhadores mais antigos, esse processo de mudança é visto como radical e de difícil adaptação.

Para os técnicos que trabalharam muitos anos com a prática da tecnologia analógica, o conhecimento e o domínio do sistema de 
funcionamento dos equipamentossão indispensáveis para se obter bons resultados na tecnologia digital. Para esses, saber que seus antigos conhecimentos não têm mais valor abala de certa forma sua postura emocional.

Alguns trabalhadores, inclusive, apresentam resistência ao ter que se desfazer daquilo que faz parte de sua história. É como se seu saber tácito o fizesse se sentir útil em seu meio de trabalho. Além disso, grande parte dos operadores defende que a prática e o conhecimento adquirido na tecnologia analógica facilitam a visão sistêmica que o novo modelo de trabalhador precisa ter para desempenhar sua função. Por outro lado, na perspectiva dos engenheiros e gerentes principalmente, a passagem pela tecnologia analógica tornou-se inteiramente dispensável, argumentando que as tecnologias analógica e digital são diferentes, e que dispõem de diferentes conhecimentos e qualificações.

Outro ponto importante apresentado e discutido nesse capítulo refere-se aos desafios à criatividade por parte dos trabalhadores, principalmente por parte daqueles inseridos na cultura da tecnologia analógica, pois, conforme relatam, sua criatividade nesse tipo de ambiência (analógica) foi "extinta”, já que demandaram outras habilidades no processo de trabalho. Aos gerentes, afirmam que sua criatividade está relacionada as novas tecnologias, defendendo o cuidado para manter o equipamento em funcionamento. A satisfação desses últimos está em função do resultado obtido com um dia de trabalho.

Conforme Bianchetti (2001), as tarefas mais pesadas e cansativas devem ser deixadas para as máquinas, mas o "perigo" está em: até onde isso não abala a capacidade ativa do trabalhador? Muitas vezes as máquinas usam de sua "inteligência artificial" e executam os "trabalhos pensantes", enquanto que o homem, sem mais 
opções, executa o trabalho sem exercer a força mental. Com as antigas revoluções nas indústrias e no trabalho, sabemos que essa problemática de adequação dos trabalhadores a novos meios de aplicação do trabalho não é uma questão nova, porém a situação atual apresenta algumas peculiaridades, como a velocidade em que tudo está acontecendo e como os trabalhadores são inseridos em um novo meio e não tem tempo para abstraírem o que está acontecendo.

As intensificações no período e na quantidade de trabalho aumentaram em proporções imensas desde o período das tecnologias analógicas até a chegada das tecnologias digitais. Segundo Bianchetti (2001), alguns depoimentos mostram que, nas tecnologias analógicas, os trabalhadores tinham um conhecimento mais específico em cima de determinada central e que, por isso, sua preocupação apoiava-se em cuidar para que essa central continuasse funcionando perfeitamente. Caso alguma coisa desse errado, ele já sabia o que fazer para reverter o problema; portanto, o trabalhador não se sentia pressionado e sua rotina era mantida sem maiores problemas.

Com a chegada das TIC, houve uma intensificação do trabalho, mesmo que a jornada de trabalho tenha sido mantida. Bianchetti (2001) afirma que, de uma forma mais genérica, observou-se que a quantidade de trabalho manual, de esforço físico, realmente pode ter sofrido diminuições, mas a quantidade de trabalho mental, de informações que um indivíduo precisa ter para realizar seu trabalho é muito maior e, consequentemente, muito mais estressante do que antes era. Com isso, o trabalhador não se enxerga preso as suas obrigações apenas no expediente de trabalho, mas também carrega suas preocupações profissionais para dentro do âmbito familiar e pessoal. 
"A qualificação num contexto de transformações tecnológicas, organizacionais e gerenciais aceleradas" é o título do quinto capítulo, no qual Bianchetti (2001) afirma que as inovações e a digitalização do quotidiano de qualquer cidadão exige que as pessoas readaptem suas vidas dentro do espaço e tempo que lhes é oferecido, tentando encaixar alta produtividade, superação tecnológica, convívio social e lazer dentro de uma agenda lotada de tarefas. Essas inovações tecnológicas alcançam também a educação escolar da nova geração que está sendo formada, abrindo um imenso vão aquilo que se aprende e aquilo que se pratica.

Para Bianchetti (2001), é imposta ao trabalhador a adaptação ao trabalho e a maneira como o desenvolve se torna pessoal de cada trabalhador, como se cada trabalhador agisse de forma intuitiva e não codificável. Esses conhecimentos, que possibilitam que o indivíduo modifique e inove o processo real do trabalho, chamam-se "qualificações tácitas".

No sexto e último capítulo, denominado "Nova tecnologias. Novas qualificações: desafios à educação", Bianchetti (2001) atesta que as TIC trazem novos debates a respeito do tempo e do espaço de trabalho, fazendo-se necessário que as formas de aprendizado também acompanhem esse desenvolvimento tecnológico. O conhecimento adquirido na escola tornou-se tão defasado que, hoje, as próprias empresas estão fazendo a função social de educadoras. As escolas não conseguem satisfazer as demandas das empresas, pois seus ensinamentos não condizem com o que as empresas buscam. A atualização e adaptação da escola é muito importante na formação dos novos trabalhadores qualificados para o mercado de trabalho.

Diante disso, o diploma de um trabalhador já não é um artifício que tenha muita força para seu ingresso no mercado de trabalho 
e o trabalho nas empresas está se tornando as ditas "aulas práticas", trazendo para o indivíduo a competência necessária para ser um bom trabalhador. A educação formal não é vista como dispensável, mas também não é suficientemente capaz de desfazer a insatisfação das empresas. O fato é que as escolas ainda ensinam os métodos antigos de funcionamento de um sistema de uma empresa, passando adiante formas superadas de trabalho.

Para concluir, Bianchetti (2001) realiza uma análise de que, com a supremacia da tecnologia digital, chegamos ao ponto de podermos falar em uma nova revolução, como sinal de grande transformação tecnológica. Falar de qualificação é uma questão muito ampla, pois essa nova fase tecnológica foi capaz de ampliar seu sentido e seus conflitos. Não basta ter conhecimentos, é preciso saber administrá-los, até mesmo como mercadoria de valor econômico, e saber aplicá-lo de forma eficaz e diferenciada, sabendo, também, administrar o espaço-tempo de construção e manifestação de qualificação tácita. A insistência em se mostrar o melhor trabalhador e se adaptar o mais rápido possível aos novos meios de trabalho pode causar estresse e outro males à saúde, já que tudo isso extrapola a capacidade de se manter o homem de pé como uma máquina.

Torna-se evidente, na análise de Bianchetti (2001), que a passagem do sistema analógico para o digital na Telesc ocorreu inicialmente por rupturas, mas que as contínuas inovações, que estão ocorrendo no interior das tecnologias digitais, estão imprimindo uma velocidade inédita ao processo de mudança. Por fim, acredita-se que será necessário um certo tempo para que as TIC sejam incorporadas pelos trabalhadores no trabalho de uma maneira mais efetiva. Uma análise que adere ao movimento da história, 
sem deixar de apreender-lhe as contradições, poderia contribuir para que as TIC fossem compreendidas como criações humanas que deveriam ser disponibilizadas a todos e colocadas a serviço da melhoria das condições de trabalho.

\section{Referência}

BIANCHETTI, Lucídio. Da chave de fenda ao laptop: tecnologia digital e novas qualificações - desafios à educação. Petrópolis: Vozes; Florianópolis: Ed. da UFSC, 2001.

\section{Notas}

* Graduada em Pedagogia na Universidade Federal de Santa Catarina. Mestranda em Educação, da linha de pesquisa Trabalho e Educação, na Universidade Federal de Santa Catarina. E-mail: <luh_turnes@hotmail.com>. 
